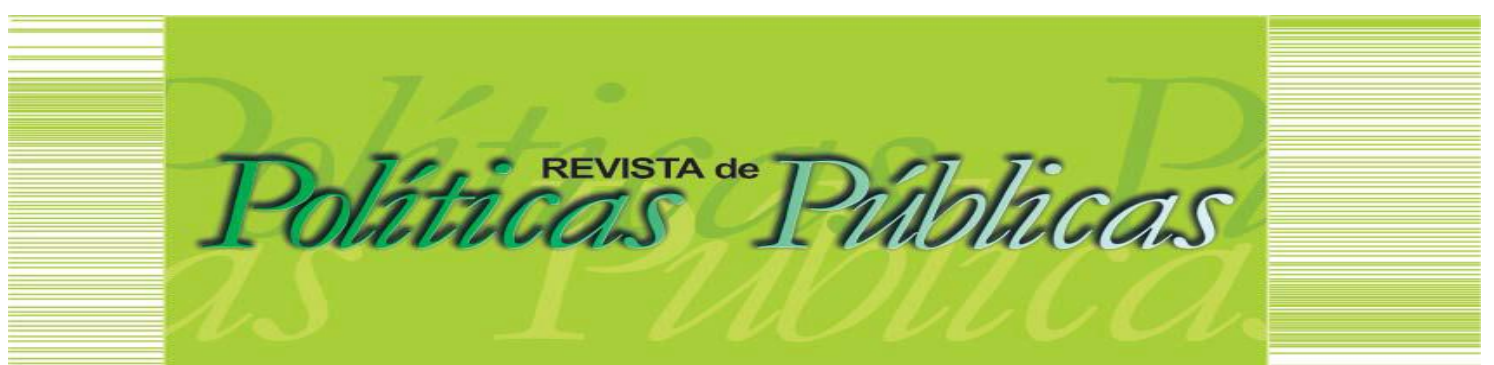

\title{
IMPLEMENTAÇÃO DA POLÍTICA DE ATENDIMENTO ÀS PESSOAS COM NECESSIDADES EDUCACIONAIS ESPECÍFICAS NOS INSTITUTOS FEDERAIS BRASILEIROS
}

\author{
Roselia Rodrigues dos Santos Lisboa ${ }^{1}$ \\ Vera Lúcia Peixoto Santos Mendes² \\ Wandillson Alisson Silva Lima $^{3}$
}

\begin{abstract}
Resumo
O objetivo deste estudo é analisar as estratégias de implementação da Política de Atendimento às Pessoas com Necessidades Educacionais Específicas(NAPNEs) nos Institutos Federais brasileiros, a partir da política formulada. Através de uma pesquisa de campo com aplicação de questionários aos coordenadores de 29 NAPNEs e análise documental dos marcos regulatórios sobre educação inclusiva, o estudo conclui que essas políticas necessitam de estratégias de implementação que incorporem: maior disponibilização de recursos financeiros, humanos e de infraestrutura; presença de equipes multidisciplinares; existência de servidores capacitados e específicos; autonomia na contratação de profissionais especializados; acesso a programas de computador para deficientes visuais e livros didáticos em Braile; e outros. Propõe ainda, aos governantes, legisladores e usuários uma [re]formulação das políticas de educação inclusiva.

Palavras-chave: Política Pública. Implementação. Atendimento Educacional Especializado. Núcleos de Atendimento às Pessoas com Necessidades Educacionais Específicas.

\section{IMPLEMENTATION OF THE POLICY ATTENDANCE TO PEOPLE WITH SPECIFIC EDUCATIONAL NEEDS IN THE} BRAZILIAN FEDERAL INSTITUTES
\end{abstract}

\begin{abstract}
The research's goal is to analyze the strategies of implementation of the Policy of Assistance to People with Specific Educational Needs (NAPNEs) in the Brazilian Federal Institutes, based on the policy formulated. A field survey was carried out with the application of questionnaires to the coordinators of 29 NAPNEs and documentary analysis of the regulatory frameworks on inclusive education. These policies need implementation strategies that incorporate: greater availability of financial, human, and infrastructure resources; presence of multidisciplinary teams; existence of trained and specific servers; autonomy in hiring specialized professionals; access to computer programs for the visually impaired and textbooks in Braille; and others. It proposes to governments, legislators and users a [re] formulation of inclusive education policies.

Keywords: Public Policy. Implementation. Specialized Educational Attendance. Centers for Assistance to People with Specific Educational Needs.

Artigo recebido em: 05/04/2019 Aprovado em: 29/10/2019 DOI: http://dx.doi.org/10.18764/2178-2865.v23n2p566-585.

\footnotetext{
1 Pedagoga. Mestra em Administração pela Universidade Federal da Bahia. Técnico em Assuntos Educacionais do Instituto Federal de Educação Ciência e Tecnologia do Norte de Minas Gerais. E-mail: roselia.pedagogia@hotmail.com

2 Bacharel em Direito. Pós-Doutora em Direito Internacional da Saúde pela Faculdade de Direito e Centro Hospitalar Universitário da Universidade de Nice Sophia Antipolis. Doutora em Administração pela Universidade Federal da Bahia. Mestra em Administração pela Universidade Federal da Bahia. Professora Titular da Universidade Federal da Bahia. PósDoutorado em Direito Internacional da Saúde pela Faculdade de Direito e Centro Hospitalar Universitário da Universidade de Nice Sophia Antípolis, França. E-mail: verapeixoto09@gmail.com

${ }^{3}$ Administrador. Doutorando em Administração na Universidade Federal da Bahia. Mestre em Administração pela Universidade Federal da Bahia. Administrador do Instituto Federal do Sertão Pernambucano - IF SERTÃO PE. E-mail: wandilson900@live.com
} 


\section{INTRODUÇÃO}

Este estudo tem como tema central a análise sobre a implementação da política pública de educação especial, mais precisamente na perspectiva dos Núcleos de Atendimento às Pessoas com Necessidades Educacionais Específicas (NAPNEs) dos Institutos Federais de Educação, Ciência e Tecnologia (IFET), que são os responsáveis pela implementação do Atendimento Educacional Especializado (AEE) na rede federal de educação profissional e tecnológica brasileira (Rede Federal).

Na Rede Federal, a implementação do AEE é competência atribuída aos NAPNEs. Estes Núcleos foram criados em 2000,pela Secretaria de Educação Continuada, Alfabetização, Diversidade Inclusão (SECADI), a partir do Programa de Educação, Tecnologia e Profissionalização para Pessoas com Necessidades Educacionais Específicas (TECNEP). Então, possibilitar o ingresso da pessoa com necessidades educacionais específicas na instituição regular de ensino é apenas o primeiro passo no longo caminho para a inclusão. Esses fatores corroboram que, além do mais, requerem estratégias para a gestão implementar ações assistenciais promotoras de acesso e permanência dos atores sociais alvos das políticas em questão.

Esta pesquisa se insere no campo das políticas públicas, com foco sobre: marcos regulatórios para a educação especial, contexto, comportamento dos atores na implementação, ideias e valores dos atores, tipologias, abordagens e o conjunto de políticas públicas que sustenta a educação inclusiva no Brasil. Dos poucos estudos encontrados sobre o AEE nos Institutos Federais, a maioria tem tratado sobre a avaliação e as contribuições e/ou legado do TECNEP e, consequentemente, do NAPNE para a ampliação das oportunidades de ingresso nas instituições de educação profissional e tecnológica e da inserção das pessoas com necessidades especiais no mercado de trabalho (ANJOS, 2006; AZEVEDO, 2007; ROSA, 2011; COSTA, 2011; BORTOLINI, 2012; SANTIAGO, 2014). Assim, não foram verificados estudos que contemplassem uma perspectiva analítica da implementação da política pública de AEE na educação profissional e tecnológica, com o foco nas estratégias e nos possíveis obstáculos na sua implementação.

Dessa forma, apresenta-se como questão de pesquisa: quais as estratégias de implementação da política de Atendimento às Pessoas com Necessidades Educacionais Específicas utilizadas pelos Institutos Federais de Educação Profissional e Tecnológica no Brasil? Para responder a essa questão, o objetivo é analisar as estratégias de implementação da Política de Atendimento às Pessoas com Necessidades Educacionais Específicas nosIFETs brasileiros, a partir da política formulada.

A relevância deste artigo consiste em fomentar o debate sobre implementação do AEE pelos Institutos Federais e, consequentemente, contribuir na melhoria do processo de implementação 


\section{IMPLEMENTAÇÃO DA POLÍTICA DE ATENDIMENTO ÀS PESSOAS COM NECESSIDADES EDUCACIONAIS ESPECÍFICAS NOS INSTITUTOS FEDERAIS BRASILEIROS}

da PP do AEE.O presente estudo perpassa um problema empírico, empenha-se para acrescentar uma contribuição ao escasso campo teórico sobre implementação da política de atendimento às pessoas com necessidades educacionais específicas nos Institutos Federais do Brasil.

\section{REFERENCIAL TEÓRICO}

Sistematizou-se esta seção em dois instantes complementares a fim de apresentar 0 arcabouço das discussões do tema. O primeiro traz as concepções das políticas públicas, sobretudo com enfoque na etapa de implementação. $O$ segundo retrata as especificidades das políticas para educação inclusiva na Rede Federal.

\subsection{Políticas Públicas: um olhar para implementação}

Em um conceito de política difundido e encontrado nos estudos de Souza (2006), a autora encontra no inglês uma definição para o termo como sendo Política (Policy) um curso de ação deliberado que guia as decisões na direção de resultados racionais.Consoante Dye (2009), a política é a luta entre grupos para influenciar as políticas públicas; e a tarefa do sistema político é administrar o conflito que ocorre entre os grupos, estabelecendo regras, negociações, equilíbrio de interesses, oficialização e cumprimento de acordos. Heidemann (2014) expõe algumas definições de política. A primeira define a política como tudo aquilo que diz respeito à coletividade, sociedade e suas organizações; a segunda, como um conjunto de processos e métodos utilizados pelos indivíduos ou grupos de interesse para se manter no poder; a terceira define a política como sendo a arte de governar e viabilizar o bem público.

A política pública é uma subárea da Ciência Política e nasceu como disciplina, nos Estados Unidos. $O$ conceito de política pública (PolicyPublic) se refere àquilo que pertence ou afeta toda a sociedade, seja de forma jurídica ou mesmo fisicamente (SOUZA, 2006). Dye (2009) aponta que política pública é o equilíbrio alcançado na luta entre grupos. Ainda nessa concepção, a política não se transforma em política pública sem que antes seja adotada, implementada e feita cumprir, e que as políticas governamentais envolvem o caráter da universalidade, enfatizando que somente as políticas governamentais dizem respeito a todos.

Mattos e Baptista (2015) concordam que as fases do processo da política pública se concentraram em cinco etapas, as quais são utilizadas até os dias atuais e que configuram a ideia de ciclo. São elas: definição da agenda; formulação da política; tomada de decisão; implementação e avaliação. Assim, a principal contribuição da ideia do ciclo é talvez a possibilidade de discernir sobre a 
existência de momentos distintos no processo de construção de uma política. Já as desvantagens estão associadas à fatal fragmentação que a ideia de fases ocasiona nas análises empreendidas.

Silva e Melo (2000), ao analisarem o processo de implementação de políticas públicas no Brasil, admitiram que os vícios de implementação de programas governamentais têm sido entendidos como fundamentais para explicar insucessos em atingir os objetivos estabelecidos em fases anteriores. Os autores argumentam que em uma visão tradicional do processo de implementação essa fase constitui o policycycle e que essa visão clássica não leva em consideração o ciclo como um processo e é implementada de cima para baixo (top down). Em uma visão menos simplista, a implementação é vista como um processo em que é retroalimentado frequentemente.

Um balanço das análises sobre ciclo de políticas públicas realizadas por Baptista e Rezende (2015) evidencia uma longa trajetória no terreno da análise de políticas públicas, com interpretações que ora convergem e ora divergem nas divisões/fases das políticas e que, nenhuma definição de análise poderia ser capaz de elucidar tamanha complexidade. Na concepção do policycycle (ciclo de políticas públicas), a implementação é concebida como uma fase do processo, não se limitando a uma fase estanque em que possa ser analisada e concebida sem a interferência das fases anteriores ou posteriores, assim como a própria denominação de ciclo evoca a mensagem de um continuum entre as fases e uma constante retroalimentação de todo o processo.

$\mathrm{Na}$ fase da implementação de políticas públicas, há uma consonância de entendimento quanto à definição, esclarecendo o momento em que os planos são desempenhados na prática, por meio da execução dos objetivos propostos diante dos problemas enfrentados pelos tomadores de decisão (PRESSMAN; WILDAVSKY, 1984; SILVA; MELO, 2000; SARAIVA, 2006; LIMA; D'ASCENZI, 2013; SECCHI, 2014). Nessa conjuntura emergem definições sobre implementação de políticas públicas que procuram clarificar essa complexa fase do ciclo. Sendo que a implementação tem a ver com a execução de atividades, permitindo que sejam alcançadas ações na obtenção de metas definidas no processo de formulação das políticas A decisão de inserção de um problema na agenda política não garante as condições para que se concretizem os ideais almejados. Tais decisões podem representar apenas um amontoado de intenções postas em leis, decretos, regulamentos, mas a materialização de ações dependerá de condições exequíveis e, para tanto, as estratégias e objetivos necessitam ser claramente definidos para que os implementadores assimilem a política e compreendam o seu papel no cumprimento da ação. Além disso, entende-se a importância das demandas da sociedade, principalmente dos grupos alvos organizados, para que a política pública seja implementada (SILVA; MELO, 2000, SECCHI, 2014).

Para reafirmar que a definição de estratégias e a clareza dos objetivos são responsáveis pelo sucesso de uma política, Lima e D'Ascenzi (2013) discorrem que é imprescindível que os 


\section{IMPLEMENTAÇÃO DA POLÍTICA DE ATENDIMENTO ÀS PESSOAS COM NECESSIDADES EDUCACIONAIS ESPECÍFICAS NOS INSTITUTOS FEDERAIS BRASILEIROS}

implementadores compreendam perfeitamente a política e saibam exatamente o que se espera deles. Contudo, a implementação vai muito além da simples execução de decisões tomadas e enseja outras tomadas de decisões, o que permeia todo o processo de implementação da política. Assim, a definição de estratégias de implementação e o conhecimento dos objetivos são parte inicial do processo de implementação, mas não oferece uma ideia exata do que de fato terá que ser feito pelos implementadores nem informa o tamanho do esforço dos atores envolvidos na política pública. 0 acompanhamento da implementação da política necessita ser realizado constantemente, para, entre outros motivos, tornar possível a identificação das razões pelas quais levou uma política a não dar certo ou a não obter os resultados esperados (RUA, 2013).

Quanto aos modelos de implementação, Rua (2013), discute que podem ser distinguidos em: modelo top-down (de cima para baixo), modelo botton-up (de baixo para cima) e os "modelos híbridos". O modelo top-down acolhe as concepções mais generalistas de implementação e é também conhecido como "Implementação Programada", tendo como primordial a acepção de que a implementação tem início com uma decisão do governo, que define a relação entre os objetivos e os meios a serem mobilizados pelos diferentes níveis da burocracia, a fim de produzir os efeitos desejados.

Na visão bottom-up, segundo Najberg e Barbosa (2006), contrariamente ao modelo topdown, o processo negocial se mantém durante a fase de implementação, provocando efeitos de baixo para cima e modificando todo o processo. Esse modelo parte dos atores sociais envolvidos na implementação da política (NAJBERG; BARBOSA, 2006). Assim, em vez de se configurar uma mera execução de tarefas oriundas do sistema político, no modelo bottom-up a implementação consiste em um conjunto de estratégias criadas pelos burocratas em nível de rua, aqui denominados de Burocrata de Médio Escalão (BME), para solucionar os problemas advindos do cotidiano (RUA, 2013; LOTTA, 2015). Por haver sinais de que coexistem na realidade situações diversas nos modelos top-down e bottom-up, o modelo hibrido surge como mais atual nos estudos sobre implementação de políticas públicas.

Lima e D'ascenzi (2013) questionam os modelos de análise acima citados, pois consideram que os mesmos superestimam a importância das normas ou a discricionariedade dos executores. Os autores propõem um novo modelo de análise de implementação, considerando que existe uma relação entre o plano e sua execução e enfatizam que é necessário contemplar essa relação. Alegam que se deve partir de uma ideia mais fluida de implementação, que considere os elementos previstos no plano e o contexto local da ação nos seguintes aspectos: as características do plano; a organização do aparato administrativo responsável pela implementação; as ideias, os valores e as concepções de mundo dos indivíduos (BMEs). Já Tummers e Bekkers (2014) destacam o poder 
discricionário dos BMEs, o que pode se intensificar se as estratégias, objetivos do plano e procedimentos não estão claramente definidos.

A análise de políticas públicas pode ser entendida como um conjunto de observações, de caráter descritivo, explicativo e normativo, acerca das políticas, que corresponde, respectivamente, às perguntas a respeito de "o que/como é", "por que é assim" e "como deveria ser" (SERAFIM; DIAS, 2012, p.127). Consoante Sechi (2014), no caso da pesquisa sobre implementação, seu foco está centrado em elementos, contornos, relações e apresenta uma opção mais descritiva e prescritiva. Dessa forma, o papel do analista estaria em poder auxiliar os formuladores a melhorar as políticas, sendo capaz de reconhecer os problemas e, se possível, propor alguma melhoria.

\subsection{Políticas para Educação Inclusiva na Rede Federal de Educação}

Até a Constituição da República Federativa do Brasil de 1988 não se evidencia uma política efetiva de educação inclusiva; a ênfase foi dada ao modelo de educação especial, em que as pessoas com deficiências tinham atendimento educacional/médico em escolas filantrópicas. Esse modelo de educação, pautado na segmentação, retira o fator contrastante das relações entre as pessoas e a escola. A educação inclusiva tem por função repor esses contrastes, pois a diversidade é a essência da humanidade, sendo assim fator fundamental para a construção da subjetividade (SILVA; COSTA, 2015).

No Brasil a educação se caracterizou como um espaço de privilégio de determinados grupos sociais, de forma que, com o tempo, uma exclusão foi ganhando força e legitimação por intermédio de ações governamentais, tornando a política educacional restritiva e reprodutora da ordem social dominante. A partir da Constituição de 1988, observa-se um crescente movimento pela inclusão, principalmente intermediado pela concepção de direitos humanos que enaltece o direito à educação e o respeito à diversidade (JANNUZZI, 2004).

Ao trazer a educação inclusiva para um campo mais restrito às pessoas deficientes, a Convenção Mundial sobre Direitos das Pessoas com Deficiências, assinada em Nova York, em 2007, e promulgada no Brasil em agosto de 2009, traz em seu texto abordagem sobre a inclusão educacional, afirmando que o Estado deverá assegurar que as pessoas com deficiência não sejam excluídas do sistema de ensino. Por esta previsão apreende-se que a rede regular de ensino não poderá oferecer resistência em receber qualquer aluno com o argumento de que não está preparada ou adequada às necessidades específicas dos alunos. Essas e outras previsões legais trouxeram mudanças significativas às escolas brasileiras tendo em vista que, no Brasil, segundo Kassar (2011) a educação especial deu-se, em grande medida, por meio de um conjunto de instituições privadas de caráter 


\section{IMPLEMENTAÇÃO DA POLÍTICA DE ATENDIMENTO ÀS PESSOAS COM NECESSIDADES EDUCACIONAIS ESPECÍFICAS NOS INSTITUTOS FEDERAIS BRASILEIROS}

assistencial, que não são considerados pertencentes à rede regular de ensino.

Faz-se necessário proporcionar a essas pessoas permanecer e concluir o curso de forma digna e condizente com seu tipo de necessidade, o que demanda apoio institucional na implementação e universalização da política de inclusão (LASTA; HILLESHEIM, 2014). Fruto de uma política pública de inclusão, o Atendimento Educacional Especializado, previsto em lei, é, portanto, obrigatório em todas as instituições de ensino públicas e é ofertado na Educação Profissional e Tecnológica, precisamente pelos IFETs, por intermédio do NAPNE, que foi criado através do programa TECNEP. Esse programa foi transformado no ano de 2010 em uma ação da SETEC/MEC, passando a ser denominado a partir de então como "AÇÃO TECNEP". Desde então, o NAPNE vem sendo implementado em todas as unidades da rede sob as condições definidas em cada instituição.

A estratégia de implementação da política de AEE nos Institutos Federais é que cada unidade estabeleça um regulamento de NAPNE e que institua um NAPNE em cada unidade dos Campi para realizar, principalmente, o Atendimento Educacional Especializado, previsto em Lei.

\section{METODOLOGIA}

Foi realizada pesquisa de natureza qualitativa, quantitativa, descritiva e exploratória. Quanto aos procedimentos de coleta de dados, utilizaram-se os documentos e os questionários (GIL, 2010). A investigação se estruturou em três fases: a primeira foi o levantamento documental, a segunda esteve concentrada na pesquisa de campo, e na terceira foram analisados os dados obtidos.

Para definição da amostra, realizou-se uma busca sistemática nos portais eletrônicos dos 38 Institutos Federais, constatando-se que 29 dispunham de Regulamentos de NAPNEs localizados em algum link dos sites. Como um dos documentos essenciais para a pesquisa documental é o Regulamento de NAPNE, este foi o primeiro critério de escolha para seleção dos pesquisados. A pesquisa foi realizada nos NAPNEs dos Institutos Federais de Educação Ciência e Tecnologia.

A criação do NAPNE é a principal estratégia para implementar a política de atendimento às pessoas com necessidades educacionais específicas nos Institutos Federais. Os Regulamentos de NAPNEs foram os documentos que deram maior fundamentação ao trabalho por conter elementos próprios de cada Instituto e constituir a principal estratégia de implementação da política pública do AEE nessas organizações.

A pesquisa de campo foi realizada, selecionando os Campi dos Institutos pelo tempo de criação. Este critério foi utilizado pela possibilidade de evidenciar as diferenças que poderiam coexistir entre Campi com maior e menor tempo de criação e/ou implementação do NAPNE. Foram realizadas inúmeras tentativas no sentido de enviar os questionários aos atuais Coordenadores de NAPNEs, 
porém os contatos nos portais estavam em sua maioria desatualizados. A finalização da coleta ocorreu em 2017, quando se obteve $62 \%$ de respostas aos questionários enviados, os quais foram: QIF2, QIF5, QIF6, QIF8, QIF9, QIF11, QIF12, QIF13, QIF14, QIF15, QIF17, QIF18, QIF20, QIF22, QIF23, QIF24, QIF27 e QIF29.

O Quadro 1 apresenta o quantitativo de respondentes aos questionários e a identificação categorizada dos Campi dos Institutos Federais e as respectivas regiões.

Quadro 1- Respondentes do questionário por Região

\begin{tabular}{|c|c|c|c|}
\hline Região & $\begin{array}{c}\text { Identificação do Instituto na } \\
\text { análise documental }\end{array}$ & $\begin{array}{c}\text { Identificação do Instituto na pesquisa de } \\
\text { campo }\end{array}$ & Total \\
\hline Centro-Oeste & IF5, IF13, IF14 & QIF5, QIF13, QIF14 & 03 \\
\hline Nordeste & IF2, IF11, IF17, IF20, IF23, IF29 & QIF2, QIF11, QIF17, QIF20, QIF23, QIF29 & 06 \\
\hline Norte & \multicolumn{2}{|c|}{ Não retornou nenhuma resposta ao questionário } & 0 \\
\hline Sudeste & IF8, IF12, IF15, IF26, IF27 & QIF8, QIF12, QIF15, QIF26, QIF27 & 05 \\
\hline Sul & IF9, IF18, IF22, IF24 & QIF9, QIF18, QIF22, QIF24 & 04 \\
\hline \multicolumn{2}{|r|}{ Total de respondentes do questionário } & 18 \\
\hline
\end{tabular}

Fonte: Pesquisa de campo, 2017.

Foi adotado o método de envio do questionário on-line através de e-mail, por permitir rapidez, flexibilidade e acompanhamento da taxa de resposta. Os Coordenadores foram previamente contatados via e-mail e solicitados a responderem ao questionário da pesquisa. Os questionários foram analisados com as mesmas referências de nomes utilizados na análise documental. Exemplo, na análise documental utilizou-se a referência IF2 e no questionário, para o mesmo Instituto Federal, foi utilizado QIF2. Os questionários foram elaborados e tabulados na plataforma Google Docs.

Foram consideradas as variáveis propostas por Lima e D'Ascenzi (2013), e, através de algumas adaptações destas propostas, foi feita a análise dos Regulamentos de NAPNEs, triangulando com as informações contidas nesses documentos com as respostas dos questionários (CRESWELL, 2010).Quanto às estratégias de análise, os dados qualitativos foram analisados mediante a técnica de análise de conteúdo (BARDIN, 2016), enquanto os dados quantitativos, mediante a escala Likert de 5 pontos e frequências simples.

Com vistas para os aspectos éticos da pesquisa, todos os respondentes, por meio do Termo de Consentimento Livre e Esclarecido disponibilizado, estavam cientes do objetivo da pesquisa e dos meios de divulgação dos resultados.

\section{DISCUSSÃO E RESULTADOS}

4.1 A Política do TECNEP: Análise das Estratégias para Implementação 


\section{IMPLEMENTAÇÃO DA POLÍTICA DE ATENDIMENTO ÀS PESSOAS COM NECESSIDADES EDUCACIONAIS ESPECÍFICAS NOS INSTITUTOS FEDERAIS BRASILEIROS}

alguns textos normativos que fundamentaram a elaboração do documento à época, expressos no próprio documento, quais sejam: Declaração Mundial sobre Educação para Todos (1990), Normas sobre a Equiparação de Oportunidades para Pessoas com Deficiência (1996), Declaração de Salamanca (1994), Constituição da República Federativa do Brasil (CRFB/1988, Art. 208) e Lei de Diretrizes e Bases da Educação Nacional (1996).

Assim, o TECNEP possui características de um Programa que foi criado especificamente para atender escolas técnicas, agrotécnicas federais, CEFETs e escolas vinculadas às Universidades (TECNEP, 2001) e, como sua criação data anteriormente à criação dos Institutos Federais, o programa não envolve o termo IFETs, embora os Institutos estejam contemplados. Ao analisar o percurso de criação do TECNEP, percebe-se que os primeiros passos alçados nesse processo são da Secretaria de Educação Especial - SEESP que, em 1999, iniciou um processo de identificação de estudantes com necessidades especiais na Rede Federal (MEC, 2000). Compreende-se a união das duas secretarias para a missão, uma vez que a SEESP seria o órgão responsável pela educação especial de forma geral, e a SETEC a responsável pela educação profissional e tecnológica em nível federal.

Além da identificação dos atores envolvidos na definição do TECNEP, outras questões merecem atenção ao se analisar a política, ou seja, a definição das estratégias de implantação e seus objetivos. Nesse sentido, ao se observar os três momentos do Programa parece não haver clareza quanto às estratégias para alcançar os objetivos da política. Houve encontros para sensibilização dos envolvidos com a educação, sociedade civil, ONGs etc., porém não se visualizam parcerias e/ou articulações com os Estados que já realizavam seu AEE com algum conhecimento. Menciona-se a relevância da experiência acumulada de alguns atores sociais, dentre eles a dos Estados e Municípios, sem, contudo, traçar as estratégias para aproveitamento dessa valiosa experiência.

Sobre o documento base de criação do TECNEP, uma questão desperta a atenção para a análise da Política: a falta de localização de informações detalhadas sobre o Programa nos sites do governo. O que o Documento-base contempla são o histórico da educação inclusiva, os marcos regulatórios sobre educação inclusiva e um relato sobre o percurso de criação do Programa, inclusive com anexação de cópia do Termo de Compromisso firmado entre as duas Secretarias do Ministério da Educação (MEC), além de relatórios de alguns eventos regionais de socialização do Programa.

As principais atividades das fases iniciais de implementação do TECNEP foram caracterizadas pela apresentação da missão do TECNEPe sensibilização pela causa pelo Diretor Geral e Coordenador Geral do Programa aos envolvidos no processo educativo, às Organizações Não Governamentais e às pessoas de modo geral identificadas com a causa das pessoas com deficiência, havendo, nesses momentos, levantamento de demandas para continuidade das atividades do programa, as quais, resumidamente, foram: criação de cursos de capacitação em LIBRAS, Braille, em 
atendimento de Pessoas com Necessidades Específicas (PNE), possibilitar o ingresso dos PNEs nas instituições de ensino, desenvolvimento de cursos de qualificação para PNE (cursos que tenham demanda de mercado), criação de fóruns estaduais sobre o tema da deficiência, captação de recursos financeiros e criação de núcleos de atendimento ao PNE nos Institutos, entre outros.

A falta de documentos disponibilizados pela SETEC para acompanhamento das ações de implementação dessas atividades iniciais do TECNEP dificultou a análise da efetivação das ações do Programa, uma vez que não se fala em números de atendimentos, em quantitativo de NAPNEs (atualizado), em recursos financeiros disponibilizados e em capacitações realizadas.

A Política Pública de Atendimento Educacional Especializado depende da articulação com outras políticas. Assim, como prever capacitação dos profissionais da Rede Federal para atendimento das PNEs sem, contudo, realizar uma política de educação permanente dos profissionais? Como incentivar os Institutos Federais a realizarem a educação inclusiva sem antes prever os entraves burocráticos à contratação de novos servidores? São alguns questionamentos que emergem sem, contudo, apresentarem soluções, questões que ficam à mercê das leis de mercado sobre oferta e demanda. Além disso, a articulação com o mercado de trabalho para absorção dos egressos seria parte da estratégia de implementação da política do AEE.O que caracterizou o grande esforço do TECNEP, desde sua criação até o momento de elaboração deste estudo, foi a criação dos NAPNEs como estratégia para a implementação da Política Pública de Atendimento Educacional Especializado.

Sobre essa questão, o que se observou nos Regulamentos de NAPNEs de alguns Institutos Federais foi uma ação que define como uma das finalidades dos NAPNEs a sensibilização da comunidade, mediante a promoção de diálogos, na busca da quebra de barreiras atitudinais, a promoção para a cultura da educação para a convivência, a organização de eventos que promovam a sensibilização, estímulo do espírito de inclusão, a formação de servidores para práticas inclusivas, a disseminação da cultura de inclusão, a inserção de temáticas de inclusão no ensino, na pesquisa e na extensão, entre outras finalidades dos NAPNEs. Apesar de se verificar que grande parte dos Institutos prevê nos Regulamentos de NAPNEs a sensibilização sobre a ideia de inclusão, entendeu-se que os Campi ainda não estão totalmente abertos quanto à inclusão e que serão necessárias mais ações nesse sentido.

Convém salientar o uso dos termos implantação/implementação do NAPNE nos Institutos, pois os termos, com muita frequência, foram empregados nos Regulamentos. A maioria dos Regulamentos menciona ações de implementação de políticas de inclusão nos Campi. Os Institutos Federais IF07, IF16, IF21 e IF23 mencionam como finalidade do NAPNE "desenvolver ações de implantação e implementação das políticas de inclusão" (Regulamento IF16). Os Institutos Federais IF10, IF14, IF19 e IF25 assinalam que uma das finalidades dos NAPNEs é "desenvolver ações de 


\section{IMPLEMENTAÇÃO DA POLÍTICA DE ATENDIMENTO ÀS PESSOAS COM NECESSIDADES EDUCACIONAIS ESPECÍFICAS NOS INSTITUTOS FEDERAIS BRASILEIROS}

implantação e implementação da Ação TECNEP" (Regulamento IF10). Já os regulamentos dos Institutos Federais IF6 e IF12 apontam entre outras finalidades apenas a implantação das políticas de inclusão pelo Núcleo.

No domínio da categoria relações de poder, outro conteúdo que chama a atenção diz respeito à diversidade de subordinação do NAPNE nos IFETs. A maioria dos Regulamentos de NAPNEs não informa sua vinculação a uma Pró-Reitoria, representando um total de 41,38\%. Dos que informaram vinculação à Reitoria, estão vinculados à Pró-Reitoria de Ensino (34,48 \%); à Pró-Reitoria de Extensão (13,79 \%) e os outros vinculam-se às duas Pró-Reitorias juntas e a outras específicas. Nos Campi a situação é um pouco diferente, pois mantêm vínculo com a Diretoria de Ensino (34,48 \%); não informaram a Diretoria de vinculação (31,03 \%); mantém vinculação direta com a Direção-Geral $(17,24 \%)$; são vinculados à Diretoria de Extensão (10,34 \%); os demais são vinculados às duas Diretorias de Ensino e Extensão e outra diretoria específica.

A vinculação ou subordinação do NAPNE na Reitoria e/ou no Campus implica estabelecer uma relação de poder paralela, como destacada por Lima e D'Ascenzi (2013), representando a estruturação dos espaços e atores locais para atuação da política. "Os implementadores adaptarão 0 que se espera ser feito ao que conseguem (ou querem) fazer" (LIMA; D'ASCENZI, 2013, p.106). Isso não poderia ser aplicável ao serviço público devido à indisponibilidade do interesse público, princípio comezinho do Direito Administrativo. O BME não pode fazer o que quer. Contudo, há o poder discricionário dos BME (TUMMERS; BEKKERS, 2014).

Além dos aspectos discricionários discutidos, fez-se necessário abordar elementos da composição das equipes de NAPNEs, já que esses elementos também circundam a alçada discricionária dentro de uma organização; para tanto, a análise focou o item estrutura e organização das equipes de NAPNEs. Dos 29 Regulamentos de NAPNEs, 27 definiram a composição dos NAPNEs formada por coordenador e equipe. Destes, identificaram-se algumas peculiaridades: a maioria dos que informou a composição por equipe definiu-a como: "multidisciplinar formada entre outros, por psicólogos, assistentes sociais e pedagogos". Os únicos Regulamentos que não definiram equipe de composição dos NAPNEs foram os IF1 e IF29. Da leitura e análise dos regulamentos foi possível visualizar a restrição que alguns Institutos fizeram à participação no NAPNE de outros membros da comunidade escolar.

Avançando na análise sobre as composições dos NAPNEs, cabe enfatizar a dedicação que é dada pelos membros das equipes aos Núcleos em termos de carga horária semanal. Sobre o assunto, verificou-se que 12 dos 29 Regulamentos informaram a disponibilidade dos coordenadores para com os Núcleos. Entre os 12, a dedicação em carga horária semanal ficou distribuída da seguinte forma: IF2 e IF27 os coordenadores dedicarão não menos que 6h semanais ao trabalho nos NAPNEs; 
IF5, IF6, IF17, IF18 e IF22 dedicarão 8h semanais; IF10 e IF26 os coordenadores terão que se dedicar por $10 \mathrm{~h}$ semanais; o IF12 determinou um quantitativo de $4 \mathrm{~h}$ a $10 \mathrm{~h}$ semanais aos trabalhos no NAPNE e; o IF4 destinou a carga horária integral ao trabalho do coordenador no NAPNE, ou seja, 40h semanais.

Os outros 17 Regulamentos não mencionaram o quantitativo de horas de dedicação do Coordenador ao NAPNE. Note-se que o único Regulamento que previu destinação de $100 \%$ da carga horária semanal ao coordenador do NAPNE foi o IF4. Esse entendimento de que o NAPNE não é só um setor a mais dentro da instituição e, portanto, carece de uma dedicação maior do que um pequeno percentual de dedicação, já demonstra uma mudança de postura na instituição e uma valorização do papel do NAPNE.

\subsection{Análise dos Marcos Regulatórios, Estrutura Organizacional, Recursos Humanos e Materiais Disponibilizados para Implementação da Política}

Os institutos federais são autarquias federais que têm como uma das suas finalidades a oferta de educação profissional e tecnológica em todos os seus níveis e modalidades (BRASIL, 2008); essa característica torna os institutos federais uma organização híbrida, heterogênea e singular. A partir desta informação, pode-se compreender que, para fundamentar suas atividades, estas organizações precisam de mais de uma instância administrativa, e isso é importante para entender o que se propõe. Neste contexto, não se constata uma regulamentação por parte do MEC, via SETEC, no sentido de apresentar fundamentação e/ou norteamento para o desempenho das atividades da educação especial para os Institutos Federais. O que se tem como fundamentação é o Programa o qual se analisa neste estudo: O TECNEP que foi o responsável pelas políticas de educação especial na Rede Federal de Educação Profissional e Tecnológica e que já não é mais um Programa e sim uma Ação, sem, contudo, explicitar claramente as estratégias de implantação da Política Pública.

Nessa direção, um primeiro ponto a ser discutido na análise dos Regulamentos diz respeito à própria definição da finalidade dos NAPNEs, que, ao ser delineada, causou uma "confusão" na descrição. Observa-se que foram descritas funções como assessoria, consultoria, proposição, planejamento, monitoramento, deliberação, execução e acompanhamento. Tendo em vista que os NAPNEs são Núcleos criados para implementar a política de Atendimento Educacional Especializado nos Institutos Federais, entende-se que a finalidade única de assessoramento, definida por grande parte dos NAPNEs, não realizará seu objetivo maior dentro da Política Pública como visto nos Regulamentos (IF1, IF6, IF7, IF8, IF10, IF12).

Essas considerações acerca da finalidade dos NAPNEs são importantes na medida em 


\section{IMPLEMENTAÇÃO DA POLÍTICA DE ATENDIMENTO ÀS PESSOAS COM NECESSIDADES EDUCACIONAIS ESPECÍFICAS NOS INSTITUTOS FEDERAIS BRASILEIROS}

que o Regulamento destes Núcleos são marcos regulatórios da instituição, cujas ações são por estes norteadas. Assim, é crucial ter clareza quanto a suas finalidades, considerando que o NAPNE é a estratégia de implementação da política pública do AEE na instituição. A estrutura organizacional, a distribuição de recursos humanos e materiais revelam muito das relações de poder existentes em uma instituição.

Dependendo do grau de formulação da política pública, haverá uma certa discricionariedade por parte dos implementadores, para adequar o que foi formulado na política pública à realidade (SERAFIM; DIAS, 2012; TUMMERS; BEKKERS, 2014).Em relação ao Regulamento dos NAPNEs, o poder discricionário dos atores da implementação foi constatado na subordinação da equipe do NAPNE, nos mecanismos de escolha dos membros, na disponibilização e/ou vinculação de recursos humanos, materiais e financeiros. No questionário foi possível identificar ainda outros aspectos dos recursos humanos e materiais.

A respeito da subordinação em esfera micro, nos Campi, embora boa parte dos Regulamentos não tenha definido como subordinação direta ao Diretor Geral, é ele quem exerce o maior poder discricionário dentro de um Campus, observadas as instâncias colegiadas, e essa discricionariedade pode ser analisada nos mecanismos de escolha dos membros dos NAPNEs. Os Coordenadores de NAPNE podem ser escolhidos pela comunidade escolar (servidores, pais e alunos) ou podem ser indicados pelo Diretor Geral.

Assim, a análise do Regulamento apontou os seguintes resultados: em 9 (nove) Institutos a escolha do Coordenador é realizada através de eleição entre os próprios membros dos NAPNEs; 6 (seis) Institutos têm os Coordenadores de NAPNEs indicados pelo Diretor Geral; 5 (cinco) são eleitos pela comunidade escolar (servidores, pais e alunos); em um Instituto a eleição acontece pela comunidade escolar, porém o resultado é ratificado ou não pelo Diretor-Geral; os demais, abrangendo oito Institutos, não informaram o mecanismo de escolha do Coordenador do NAPNE.

A escolha do Coordenador realizada através de eleição, seja pela comunidade escolar ou entre os membros do NAPNE, indica um menor grau de discricionariedade do gestor sobre o tema, e isso ficou evidente em aproximadamente $48 \%$ dos regulamentos analisados. Ao se candidatar para participar de um processo eleitoral o individuo em algum momento fez uma escolha e subentende-se que existe uma afinidade e/ou predisposição para a função que vislumbra exercer, e isso, em se tratando de NAPNE, é de extrema importância, visto que o trabalho com o AEE requer mais do que dedicação, requer sensibilidade, habilidade e conhecimento para a missão. Do total de Regulamentos examinados 20\% definem que o Coordenador deve ser indicado pelo Diretor Geral, $32 \%$ não informaram e o restante informou outra forma de escolha.

Outros fatores que demonstraram um maior ou menor grau de discricionariedade do 
Gestor referem-se aos recursos humanos e materiais para instalação, manutenção e apoio às atividades dos Núcleos. Em geral, os Regulamentos foram muito genéricos ao abordarem esse tema, poucos definiram com maior detalhamento a destinação dos recursos ao NAPNE. Sete dos 29 Regulamentos (IF4, IF5, IF6, IF12, IF13, IF14 e IF15) estabeleceram que os NAPNEs devem ter assegurados pelos Campi uma sala para atendimento, como pode ser visto nos IF4 e IF6 respectivamente: "O local a ser instalado o NAPNE é um espaço institucional acessível, de acordo com a Norma Brasil 9050 da ABNT, com sala específica para receber, acolher e garantir o AEE das pessoas com necessidades específicas na instituição" (IF4, 2014). O NAPNE deverá dispor de infraestrutura necessária...tais como: "a) sala própria com acessibilidade física, espacial e mobiliária; b) Telefone, computadores em rede e softwares específicos; c) Recursos de tecnologia assistiva para apoio às PNEs" (IF6, 2015).

Os demais Regulamentos salientam uma maior generalização ao prever que os Campi deverão disponibilizar infraestrutura adequada ao funcionamento dos Núcleos (IF1, IF2, IF3, IF7, IF8, IF9, IF10, IF11, IF16, IF19, IF22, IF23 e IF28) e outros não mencionaram (IF17, IF18, IF20, IF21, IF24, IF25, IF26, IF27 e IF29).Dentre todos os Regulamentos examinados, apenas três, (IF2, IF5 e IF6) indicaram, além da infraestrutura necessária, uma sala de Recursos Multifuncionais para o AEE. Outros três Regulamentos preveem a destinação do percentual de 1\% dos recursos dos Campi para as ações de inclusão sendo eles: IF2, IF5 e IF12 como pode ser exemplificado: "Os recursos anualmente destinados as ações de inclusão social nunca inferiores a 1\% do orçamento do Campus." (IF5, 2013).

Todos os aspectos mencionados compreendem uma determinada discricionariedade do gestor, pois mesmo que os Regulamentos façam suas previsões, e isso cria respaldo para as equipes de NAPNEs cobrarem, as ações dos gestores passarão boa parte das vezes, pelo crivo da disponibilidade, da oportunidade e da vontade dele.

\subsection{Análise da Implementação da Política pelos Coordenadores de NAPNEs}

Objetivando verificar como os Coordenadores dos NAPNEs avaliam o processo de implementação da política, bem como o que sugerem para melhorias nos resultados do AEE, foi aplicado questionário com questões abertas e fechadas. No intuito de traçar o perfil dos sujeitos deste estudo, foram traçadas algumas questões no questionário que dizem respeito ao Instituto Federal de onde são, ao cargo efetivo de ocupação na instituição, tempo de coordenação no NAPNE, à formação acadêmica e ao gênero.

Quanto ao cargo efetivo ocupado, o perfil profissional dos Coordenadores de NAPNEs nos Institutos Federais é caracterizado por: Pedagogos (06), Assistentes em Administração (03), 


\section{IMPLEMENTAÇÃO DA POLÍTICA DE ATENDIMENTO ÀS PESSOAS COM NECESSIDADES EDUCACIONAIS ESPECÍFICAS NOS INSTITUTOS FEDERAIS BRASILEIROS}

Bibliotecário (01), Docentes (03), Técnicos em Assuntos Educacionais (02), Assistente Social (01), Psicólogos (02). Percebe-se uma grande variação na composição dos Núcleos, mas houve prevalência de profissionais ligados diretamente ao ensino, como os Pedagogos.

No que se refere ao tempo de exercício de Coordenação no Núcleo, obteve-se uma variação de quatro meses a seis anos de Coordenação(grifo nosso). Quanto à formação dos Coordenadores dos Núcleos, além das formações profissionais inerentes aos cargos efetivos, conforme cada caso, foram obtidos os seguintes resultados: em nível de graduação 05 Licenciados (pedagogia/química/letras) e 04 bacharéis (psicologia/ assistência social/gestão pública), 04 especialistas (Especialista em educação de Surdos/Psicologia Clínica e Institucional/ Coordenação e Supervisão Pedagógica) e 03 mestres (Educação e Gestão do Ensino Agrícola/Educação/Não informou).

Ao serem questionados sobre o cumprimento do papel do NAPNE nos Institutos, $72 \%$ dos respondentes concordaram que o NAPNE cumpre adequadamente sua função; 16,7\% concordaram plenamente, 5,6\% indecisos e 5,6\% discordaram (grifo nosso). A análise das respostas pode indicar que: a) os NAPNEs podem não ter expressado adequadamente suas finalidades nos Regulamentos e daí terem seu papel minimizado dentro da instituição, o que contribuiu para o cumprimento dele; b) a coordenador que está na atual gestão não quis demonstrar que existe uma falha na sua função, ou seja, não admite que o NAPNE não está cumprindo sua função, pois isso implicaria aceitar que ele ou sua equipe não desempenham o papel adequado; c) concordar que, para a grande maioria dos respondentes, o NAPNE cumpre adequadamente sua função na instituição.

Entende-se que para o cumprimento de suas funções alguns pontos são fundamentais, principalmente no que se refere à estruturação dos Núcleos. Verificou-se que existe uma incoerência entre as respostas dadas pela maioria dos Coordenadores, $72 \%$, ao afirmarem que o NAPNE cumpre adequadamente o seu papel e as respostas dadas às questões que detalham matérias da implementação dos Núcleos.

A maioria discorda e/ou discorda plenamente que a quantidade de membros da equipe do NAPNE é suficiente para o trabalho no Núcleo. A maioria dos respondentes discorda e/ou discorda plenamente que o Campus tenha cumprido o que foi previsto no regulamento do NAPNE sobre a composição da equipe. A maioria discorda e/ou discorda plenamente que o NAPNE seja uma prioridade financeira da instituição. Apenas a metade concorda ou concorda plenamente que as demandas do NAPNE são atendidas na instituição. A maioria não possui sala de recursos multifuncionais e discorda e/ou discorda plenamente que a instituição 0 oferte adequadamente 0 AEE aos estudantes dos ensinos técnico e superior (grifo nosso).

Isso posto, conforme avaliação dos Coordenadores dos NAPNEs, este Núcleo, embora 
seja a estratégia de implantação da Política do $\mathrm{AEE}$, não apresenta as condições estruturais e de funcionamento para cumprir adequadamente o ofício para o qual foi criado, uma vez que a instituição deixa de priorizar algumas ações importantes para efetivação das atividades do Núcleo. Nesse sentido, observa-se que as respostas à afirmativa sobre o cumprimento do papel do NAPNE não consideraram o contexto de implementação da política. No entanto, como não há clareza na definição das especificidades do Programa TECNEP e não se encontrando tais condições na legislação específica do AEE para os Institutos Federais, condições essas elencadas por Lima e D'Ascenzi (2013), não se pode atribuir um sobrepeso à responsabilidade dos Coordenadores dos NAPNEs.

Para extrair melhor as visões dos Coordenadores dos NAPNEs foram inseridas no questionário algumas perguntas abertas para as quais os Coordenadores pudessem se expressar livremente. Quando questionados sobre a participação do Campus na construção do regulamento do NAPNE responderam $\operatorname{sim}(70,6 \%)$ e não $(29,4 \%)$. Constatou-se que a maioria dos respondentes confirmou a participação do Campus na elaboração do Regulamento do NAPNE.

No que se refere à proposição de alteração do regulamento do NAPNE tem-se que: concordo $(61,1 \%)$; indeciso (16,7\%); discordo (11,1\%)"; concordo plenamente $(11,1 \%)$.Verifica-se que apesar de a maioria dos Coordenadores indicarem que houve participação do seu Campus na construção do regulamento de NAPNE, o Regulamento necessita de alterações, seja por elementos mal dispostos no documento, seja por situações extras constatadas após a aprovação do Regulamento. Não foram encontrados nos Regulamentos informações sobre tempo para revisão do documento, porém muitos deles indicam que alterações podem ser feitas, desde que submetidas às instâncias superiores dos Institutos.

No que se refere à opinião dos Coordenadores de NAPNEs sobre os obstáculos enfrentados na realização do trabalho nos Campi, tem-se que foram recebidas 16 respostas e dois Coordenadores não responderam. Entre as respostas foram citados os seguintes obstáculos ao trabalho do NAPNE:

Falta e/ou limitação de recursos; falta de formação/capacitação; falta de dedicação exclusiva; resistência dos servidores (professores e técnicos) ao trabalho do NAPNE; falta de colaboração da parte docente; pouca sensibilização da comunidade escolar; pouco apoio dos gestores; escassez de servidores; falta de interesse no trabalho do NAPNE; falta de estrutura adequada e; falta de interesse institucional. (QIF5, QIF8, QIF9,QIF11, QIF13, QIF14,QIF20, QIF22, QIF24,QIF26, QIF27, QIF29).

Todos os itens relatados configuraram, segundo análise dos coordenadores dos NAPNEs, como fatores de dificuldade ao desenvolvimento do trabalho nos Núcleos. Verifica-se que as dificuldades permeiam todas as instâncias, desde estudantes, passando por técnicos administrativos e 


\section{IMPLEMENTAÇÃO DA POLÍTICA DE ATENDIMENTO ÀS PESSOAS COM NECESSIDADES EDUCACIONAIS ESPECÍFICAS NOS INSTITUTOS FEDERAIS BRASILEIROS}

professores, por gestores e atingem toda a instituição.

Destaque para essa questão é dado ao que se indicou como obstáculo a "Interesse Institucional", pois todos os outros obstáculos nascem de lacunas que circundam o interesse institucional. Certamente que, nos Institutos e Campi onde houve um empenho da instituição na implementação da política pública de AEE, o NAPNE teve menos dificuldades em realizar seu trabalho.

\section{CONCLUSÃO}

O caminho percorrido para responder à questão principal deste estudo direcionou-se para os marcos regulatórios referentes à Política de Inclusão do Atendimento Educacional Especializado (AEE), principalmente os Regulamentos dos NAPNEs, o Programa TECNEP, a análise documental e os resultados dos questionários aplicados aos Coordenadores dos Núcleos nos IFETs.

No que diz respeito aos marcos regulatórios, a análise da legislação sobre o AEE não considera as especificidades institucionais dos IFETs. Ressalte-se ainda que o Programa TECNEP, que foi criado para impulsionar a implementação do AEE nos IFETs, não apresentou o detalhamento das ações. Isto pode ter ocorrido pelo fato de o mesmo não ter sido institucionalizado como uma política pública, ou prioridade nas agendas dos governos.

No que se refere ao contexto, de fato, este não agrega condições gerais de implementação, pois além de não possuir a infraestrutura necessária, não considera as especificidades dos usuários dos Institutos Federais. Os NAPNEs não atendem adequadamente as demandas que thes são atribuídas, devido principalmente aos hiatos existentes na formulação das suas diretrizes como estratégia dentro dos próprios Institutos. Significa que ao serem definidos os Regulamentos Internos, as ações do Núcleo e suas respectivas infraestruturas não houve o cuidado em dimensionar as necessidades para o seu pleno funcionamento.

Como recomendações de melhorias para os Institutos Federais foram apresentadas as sugestões estratégicas dos coordenadores dos NAPNEs para implementação, tais como: a) Maior disponibilização de recursos financeiros aos Campi para que possam ser adquiridos materiais didáticos e tecnologias assistivas, além da necessidade de que seja disponibilizada uma dotação orçamentária para os Núcleos; b) Presença de equipes multidisciplinares nos Campi, trabalhando com os NAPNEs bem como liberação de carga horária dos membros para participação ativa no trabalho do Núcleo; c) Destinação de função gratificada aos Coordenadores dos NAPNEs; d) Existência de servidores capacitados e específicos para os NAPNEs; e) Qualificação das equipes dos NAPNEs, mediante criação de um programa contínuo de capacitação de servidores dos NAPNEs; f) Capacitação para toda a comunidade dos Institutos, incluindo docentes, técnicos e discentes; g) Adequação arquitetônica da 
infraestrutura, conforme padrão exigido pela NR 9050 de 2004; h) Maior envolvimento e sensibilização da comunidade acadêmica; i) Adoção de um fluxo de atendimento, reuniões periódicas da equipe para planejamento, atendimento individualizado e acompanhamento sistemático durante toda a trajetória acadêmica dos discentes, inclusive apoio à sua inserção no mercado de trabalho; j) Autonomia na contratação de profissionais de acordo com a demanda, ainda que a contratação ocorra por terceirização; k) Acesso dos Campi a programas como computador para DVs (Deficientes Visuais) e livros didáticos em Braile.

Por fim, propõe-se aos governantes, legisladores e usuários uma [re]formulação das políticas de educação inclusiva e AEE, priorizando: a estratégia de implementação da política mediante os NAPNEs, articulação com o mercado de trabalho para inserção dos egressos dos cursos, observação do contexto e das especificidades dos IFETs em cada região, maior dotação financeira da Secretaria de Educação Profissional e Tecnológica destinada à Política Pública de AEE nos Institutos. Além da capacitação permanente de Recursos Humanos, investimentos em infraestrutura e elaboração de manuais de procedimentos, definição de fluxo de atendimento, orientação pedagógica nos NAPNEs e tomada de decisão baseada em avaliação sistemática da política.

Como limite desta pesquisa, reconhece-se a necessidade de um maior aprofundamento na teoria das fases do ciclo de Políticas Públicas, principalmente na fase da formulação de política pública. Em uma perspectiva futura, os resultados desta pesquisa poderão contribuir para a reformulação da Política de Inclusão tendo em vista as proposições para minimizar as dificuldades enfrentadas pelos Institutos Federais.

\section{REFERÊNCIAS}

BAPTISTA, T. W. F.; REZENDE, M. A ideia de ciclo na análise de políticas públicas. In: MATTOS, R. A.; BAPTISTA, T. W. F.(orgs.). Caminhos para análise das políticas de saúde. 1. ed. Porto Alegre: Rede unida, p. 138-172, 2015.

BARDIN, L. Análise de conteúdo. São Paulo: Edições 70, 2016.

BRASIL. Constituição da República Federativa do Brasil. Brasília, DF: Senado, 1988.

. Lei $\mathrm{n}^{0}$ 9.394, de 20 de dezembro de 1996. Dispõe sobre a Lei de Diretrizes e Bases da Educação. Brasília, 1996. 


\section{IMPLEMENTAÇÃO DA POLÍTICA DE ATENDIMENTO ÀS PESSOAS COM NECESSIDADES EDUCACIONAIS ESPECÍFICAS NOS INSTITUTOS FEDERAIS BRASILEIROS}

CRESWELL, J. W. Projeto de pesquisa: métodos qualitativo, quantitativo e misto. Tradução: Magda Lopes. 3. ed. Porto Alegre: Artmed, 2010.

DYE, T. D. Understanding Public Policy. Englewood Cliffs, N.J. Prentice Hall, 1984.

. Mapeamento dos modelos de análise de políticas públicas. In: HEIDEMANN, F. G. e SALM, J.

F. (org.). Políticas Públicas e Desenvolvimento: Bases epistemológicas e modelos de análise.

Brasília: Editora Universidade de Brasília, cap. 3, p. 99-132, 2009.

GIL, A. C. Como elaborar projetos de pesquisa. 5. ed. São Paulo: Atlas, 2010.

HEIDEMANN, F. G. e SALM, J. F. (org.). Políticas Públicas e Desenvolvimento: Bases

epistemológicas e modelos de análise. Brasília: Editora Universidade de Brasília. 3. ed. 2014.

JANNUZZI, G.M. A Educação do Deficiente no Brasil: dos primórdios ao início do século XXI Campinas. Autores Associados, 2004.

KASSAR, M. de C. M. Percursos da constituição de uma política brasileira de Educação Especial inclusiva. In: Edição Especial da Revista Brasileira de Educação Especial, v. 17, p. 41-58, Marília/SP, maio/ago. 2011.

LASTA, L.L.; HILLESHEIM, B.Políticas de inclusão escolar: produção da anormalidade. Psicologia \& Sociedade, v. 26, (n. spe.), p. 140-149. 2014.

LIMA, L.L.; D'ASCENZI, L. Implementação de políticas públicas: perspectivas analíticas. Revista de Sociologia e Política, v. 21, n. 48, p. 101-110, 2013.

LOTTA, G. S; PIRES, R. R. C.; OLIVEIRA, V. E. Burocratas de Médio Escalão: novos olhares sobre velhos atores da produção de Políticas Públicas. In: CAVALCANTE, P. L. C.; LOTTA, P. S. (org.). Burocracia de Médio Escalão: perfil, trajetória e atuação. Brasília: ENAP, p.23-55, 2015.

MATTOS, R. A.; BAPTISTA, T. W. F.(orgs.). Caminhos para análise das políticas de saúde. 1. ed. Porto Alegre: Rede unida, 2015.

NAJBERG, E. BARBOSA, N.B. Abordagens sobre o processo de implementação de políticas públicas. Segundo Encontro de Administração Pública e Governança (EnAPG). São Paulo, nov. 2006.

PRESSMAN, J. L.; WILDAVSKY, A. Implementation: how great expectations in Washington are dashed in Oakland. 3. ed. Berkeley: University of California, 1984.

RUA, M. G.; ROMANINI, R. Para Aprender Políticas Públicas. (Vol. 1: Conceitos e Teorias). IGEPP, 2013.

SARAVIA, E.; FERRAREZI, E. (orgs.). Políticas Públicas. Brasília: ENAP, v. 2. 2006

SECCHI, L. Políticas públicas: conceitos, esquemas de análise, casos práticos. 2. ed. São Paulo: Cengage Learning, 2014.

SILVA, P. L.B; MELO, M. A. B. 0 processo de implementação de políticas públicas no Brasil: características e determinantes da avaliação de programas e projetos. UNICAMP, 2000. 
Roselia Rodrigues dos Santos Lisboa, Vera Lúcia Peixoto Santos Mendes e Wandillson Alisson Silva Lima

SERAFIM, M.; DIAS, R. Análise de política: uma revisão da literatura. Cadernos Gestão Social, n. 3 , v.1, p.121-134, 2012.

SOUZA, C. Políticas Públicas: uma revisão da literatura: Sociologias, Porto Alegre, ano 8, n.16 p. 2045, jul/dez. 2006.

TUMMERS, L. G.; BEKKERS, V. J.J.M. Policyimplementation, street-

levelbureaucracyandtheimportanceofdiscretion. Public Management Review. v.16, n.4, p. 527-547, 2014. 